\title{
LIMITES, TRADUÇÕES E AFETOS: PROFISSIONAIS DE SAÚDE EM CONTEXTOS INDÍGENAS
}

\author{
Pedro Paulo Gomes Pereira
}

Michel Taussig analisou, num artigo de grande influência na área de antropologia da saúde (1992), o denominado "processo de reificação da enfermidade". Reificação designa a coisificação do mundo, das pessoas e da experiência, e assinala o movimento pelo qual as relações entre pessoas se transformam em coisas. Nas sociedades contemporâneas tudo funciona de forma a negar as relações humanas encarnadas nos sintomas, signos e terapias. As doenças e as técnicas de cura, no entanto, não são apenas naturais, mas signos de relações sociais disfarçados em coisas naturais. Eis então o dilema moderno: sustentar exaustivamente e por todos os meios que os órgãos corporais são apenas coisas e, ao mesmo tempo, insistir sobre o significado social do mal-estar.

As doenças como símbolos e os médicos como intérpretes desses símbolos são denegados por uma ideologia que considera a enfermidade como coisa e substância em si mesma. A prática médica é maneira importante de manter a negação das relações sociais e de operar a coisificação sob a égide da ciência. ${ }^{1}$ Essa negação produz "grotescas confusões" que transformam as relações sociais em coisas e retiram o caráter histórico e humano da enfermidade. Taussig discorre sobre: o sofrimento de pacientes; a leitura objetificadora dos médicos e demais profissionais de saúde; a incomunicabilidade originada da não percepção dos enunciados; o isolamento, a perda da autonomia dos pacientes nos hospitais. A internação hospitalar torna-se uma zona de combate onde se desenrolam disputas de poder e definições sobre a doença - processo que conduz à alienação do enfermo. A organização clínica canibaliza o potencial curativo que reside na intersubjetividade de paciente e curador. A realidade clínica mostra, enfim, a construção e a reconstrução clínica de uma realidade convertida em mercadoria. A medicina humanística é, portanto, um oximoro.

Não obstante a força da poderosa narrativa de Taussig, que descreve a moderna coisificação e fetichização médica do corpo tomado como signo 
social, e apesar do apelo de seus argumentos, no decorrer de uma pesquisa sobre tecnologias biomédicas, que venho desenvolvendo desde 2008, deparei-me com um insistente questionamento em relação a determinada visão que compreende os profissionais de saúde unicamente como opressores. A universidade da qual faço parte, Universidade Federal de São Paulo (Unifesp), colabora na assistência à saúde dos povos indígenas do Parque Indígena do Xingu (PIX) desde 1965, reunindo profissionais de diversas áreas no Projeto Xingu. Desde essa época, equipes multidisciplinares - integradas por médicos, enfermeiras, nutricionistas, dentistas - promovem ações de saúde, tais como: enviar profissionais ao PIX com o objetivo de realizar vacinações e atender a ocorrências clínicas; estreitar vínculos com o Hospital São Paulo (HSP) na busca de suporte aos casos que necessitam de cuidados clínicos ou cirúrgicos especializados; administrar o "Ambulatório do Índio" em São Paulo, entre outras.

Os profissionais de saúde ligados ao Projeto Xingu e ao Ambulatório do Índio passaram a me procurar com o objetivo de narrar suas experiências e debater sobre seu papel e sua atuação na saúde indígena. Resolvi levar a sério o que tinham para me dizer e, alterando o foco inicial da pesquisa, concentrei meus esforços em compreender as indagações e os problemas dos profissionais que trabalhavam com saúde indígena (Pereira 2012). Passei então a registrar sistematicamente as narrativas - muitas em extensas entrevistas e depoimentos que foram se sucedendo em distintos locais, como Ambulatório do Índio, dependências do Projeto Xingu, Departamentos da Universidade, polos de formação em saúde indígena, entre outros. Participei também de vários eventos: palestras, oficinas e um curso de Especialização em Saúde Indígena, organizado pelo Projeto Xingu. Realizei a pesquisa do início de 2008 ao final de 2011, por meio de observação participante, entrevistas e acompanhamento da vida cotidiana dos profissionais de saúde.

Logo no início das investigações, um médico me disse algo que eu iria escutar repetidas vezes ao longo da pesquisa: "a sensação é que neste tipo de discurso ora somos opressores, ora não existimos". Certo dia, por exemplo, distribuí o mencionado texto de Taussig para um grupo composto por médicos sanitaristas, nutricionistas, psicólogas, enfermeiras, que se mostrou animado com a discussão. Se houve consenso sobre as críticas à medicina e à "objetivação da doença", fui alertado para a ausência, no referido texto, de profissionais de saúde "como atores do processo de saúde". Segundo eles, médicos e enfermeiras quando apareciam no artigo de Taussig estavam sempre sob suspeita. O texto construía um paciente (no caso, uma mulher) envolto numa multiplicidade de participações e de interpretações sobre o adoecimento e sobre a vida, enquanto a imagem dos profissionais de saúde permanecia 
estática e vinculada a atitudes autoritárias. Esse tipo de argumentação aborrecia meus interlocutores - que não se enxergavam na narrativa de Taussig nem nas ações dos profissionais de saúde nela descritas. ${ }^{2}$

Esse questionamento era recorrente. Fui interpelado pelas indagações de meus interlocutores que se recusavam a pensar suas atuações apenas como forma de operacionalização da reificação da enfermidade. Essas interpelações dos profissionais que trabalhavam com saúde indígena sinalizavam que esse tipo de experiência com a alteridade proporcionava modificação em seus modos de pensar e de agir — sobretudo se comparados aos encontrados nos hospitais. E eles insistiam nessa diferença. Distante da paisagem desenhada por Taussig, pouco a pouco foram surgindo diante de mim: médico que, acometido por enfermidade grave e tendo que se submeter à intervenção cirúrgica, só aceitou o procedimento com a presença de Encantados Pankararu; enfermeiras que dedicaram a vida profissional e pessoal à tarefa de atuar em sociedades indígenas; médicos que realizavam curas espirituais e outros que seguiram eles próprios terapias propostas por xamãs; e assim por diante.

Esse quadro me levou às seguintes perguntas: O que acontece com profissionais de saúde que se veem diretamente relacionados a concepções diferenciadas de corpo, saúde e doença? O que sucede quando as práticas de saúde se dão num processo de tradução da própria conceituação do que seja saúde? De que forma esses profissionais são afetados por essa experiência com a alteridade radical? Sem qualquer intenção de ser exaustivo ou de abordar todas as nuances dessas indagações, e assumindo antecipadamente a parcialidade da empreitada, este texto busca refletir sobre estas perguntas. Trata-se de voltarmo-nos simetricamente (Latour 1997) àqueles que, presentes na paisagem geral da saúde indígena, por vezes desaparecem em nossos relatos ou são enquadrados de forma homogênea, sem o cuidado com suas especificidades. A esperança é que esse movimento permita apresentar um pouco da complexidade dos profissionais de saúde, dos problemas que abarcam suas atuações em sociedades indígenas e de suas concepções do que seja o próprio trabalho a ser efetuado.

No que se segue, vou explorar essas indagações, dividindo o texto em quatro seções. Nas duas primeiras, vou me deter nas histórias de uma médica e de uma enfermeira. ${ }^{3} \mathrm{Na}$ seção subsequente, analiso a experiência dessas profissionais, destacando em suas narrativas motivos constantes, que nos contam algo sobre limitações, limites e processos de tradução. Discussão esta que me conduz, em seção imediatamente posterior, a levar a sério a possibilidade de os profissionais que trabalham com saúde indígena serem afetados. Por fim, sustento que o cenário descrito talvez possa 
matizar a percepção de uma biomedicina homogênea e de profissionais de saúde exclusivamente vinculados ao poder - sempre envoltos em relações reificadas e reificadoras.

\section{Daniela e os limites da biomedicina}

Daniela nasceu em 1967, na cidade de São Paulo. Médica, formada na Unesp de Botucatu, optou por uma especialização em Saúde da Família. A vinculação de Daniela com a temática indígena é uma constante. Em todos os momentos, procura explicações para seu "desejo de se dedicar à causa indígena". Os "sinais" já estavam presentes desde criança. Com mais ou menos 11 anos, em plena época da Ditadura Militar, na escola municipal onde estudava, os professores de história subitamente desapareciam. Esses professores entraram na imaginação de Daniela de forma fantasiosa e incitante. E foi um deles que comentou sobre os dilemas dos índios no Brasil, falando sobre "a dizimação das populações indígenas". "Lembro-me de ter que sair da sala com um grande mal-estar quando [o professor] abordou o tema da questão indígena", asseverou Daniela. Assim, suas narrativas tecem uma história na qual o vínculo com a temática indígena a acompanhou desde a infância. Daí as constantes tentativas de elucidar esse vínculo: a memória busca uma explicação que remete a um tempo anterior às mencionadas aulas.

De família grande, mesmo pobre, eu viajava muito para a casa de tios, irmãos de minha mãe. Um deles, muito querido, morava no Mato Grosso e passei muitas férias junto com nove primos numa casa de madeira de poucos cômodos sem forro. Apesar de estar na capital, naquele tempo o Mato Grosso era "terra de ninguém"... Lembro-me de ouvir alguns vizinhos do meu tio contarem que matavam jacarés com quatro palmos de olho a olho e, ao mesmo tempo, diziam quantos bugres tinham alvejado. Só mais tarde eu atinaria que "bugre" não era um tipo de peixe, mas índios.

As imagens reconstruídas pela memória associam índios e necessidade, e estão repletas de cenas de violência. As imagens indicam situações de vulnerabilidade nas quais urge intervir. É no processo de intervenção que surge a medicina. Se desde a juventude Daniela afirmava o desejo de "trabalhar com índios", em algum período de sua história acredita que, "se fosse médica, poderia contribuir melhor, já que os índios estavam 'morrendo'". A medicina é, assim, posterior à decisão de se voltar para a temática indígena, associada à ideia de resgate e com tom de missão. 
Lembro-me do momento exato da decisão. Eu era muito, muito nova. O pensamento se encaixou com perfeição. [...] Algumas outras influências também contribuíram: minha mãe era espírita, e fizemos muitas visitas a instituições de assistência. Cresci com grande interesse sobre a questão indígena e tudo sobre o assunto me atraía. Provavelmente me fujam outros fatores que fizeram a medicina e a questão indígena entrarem na minha vida, mas durante toda a faculdade mantive a intenção.

Essas narrativas, de tom marcadamente soteriológico, constroem firme decisão e moldam a vida profissional de Daniela: uma semana após receber o diploma pela Unesp já estava no Acre e, a partir daí, esteve sempre envolvida com saúde indígena. Depois da experiência no Acre, inicia um trabalho no Xingu. Permaneceu também algum tempo trabalhando na formação de Agentes Indígenas de Saúde. Prestou residência em Saúde Pública em Botucatu, mas acabou se dirigindo a Rondônia para trabalhar num projeto com os Suruí e os Cinta Larga. Ao voltar a São Paulo, chegou à Aldeia Guarani do Jaraguá, onde está trabalhando até hoje. Esse tour de force nem de longe dá conta de uma rica trajetória. De qualquer forma, a opinião dela é clara: "sempre estive vinculada à saúde indígena, mesmo quando não estava".

Pensando nesse envolvimento, nas narrativas que insistem em alçar na memória um vínculo com a temática indígena, e com a intenção de indagar como o contato com a alteridade radical se manifestaria num profissional de saúde, solicitei a Daniela que me contasse um evento importante, que considerasse significativo de sua experiência com sociedades indígenas. Ela narrou a seguinte história.

Para mim é difícil escolher dentre tantas histórias vivenciadas a que melhor exemplificasse as crenças como aspecto relevante para intervenção, pois minha vivência em comunidades indígenas me ensinou muito sobre a importância de conhecê-las e experimentar um olhar a partir delas. No momento, gostaria de compartilhar um episódio que começou numa família e acabou por se disseminar pela aldeia toda.

Daniela estava trabalhando com os Caiapó, na aldeia Kapoto. Ela tinha 26 anos. Era noite e dormia nas ocas devido ao medo dos alojamentos distantes das aldeias sempre sujeitos a ataques de onça. Acordou sonolenta no meio da noite. De início, não conseguia compreender a cena que via: uma jovem adolescente se debatendo na rede e cercada de várias pessoas. Viu-se impelida a levantar, pois a cena não manifestava sinal de terminar. Pensou de início se tratar de uma crise epiléptica ou alguma enfermidade por ela conhecida, e perguntou se poderia ajudar. 
Soergueu-se para enxergar melhor. Percebeu que a moça se debatia e muitas pessoas tentavam contê-la com dificuldades. Nesse instante, um homem mais velho disse à Daniela que não se preocupasse, porque era "doença de índio". "Essa categoria doença de índio trata das coisas", afirmou Daniela, "que nós médicos não conseguimos entender nem resolver". ${ }^{4}$ Mas, ainda assim, a médica buscou entender a situação e o porquê de estarem tentando conter aquela moça. A explicação recebida ampliou a sua curiosidade, dado o seu caráter genérico e inconcluso: "se não a contivessem, [a jovem caiapó] iria para o mato e não voltaria mais, e seria perigoso para ela". Como a situação perdurou por mais algum tempo, Daniela retornou à rede, mas não conseguiu dormir, preocupada. No dia seguinte examinou a moça. A jovem caiapó não falava português, e o tradutor indígena dizia que ela nada sentia e nem conseguia descrever o que acontecera à noite. Uma realidade que intrigava Daniela.

O trabalho da médica era voltado à detecção de tuberculose, pois havia muitos casos na aldeia naquela época. Daniela era a única médica ali, e os agentes indígenas falavam pouco o português - situação que a levava a depender de tradução para quase todos os afazeres. Era uma época conturbada. Muitos aviões de garimpeiros assediavam as lideranças com o objetivo de procurar ouro na região. Traziam pilhas, carne de frango e outros produtos de escambo. Diante da situação, o trabalho na área de saúde era intenso.

Tão intenso que Daniela dormia em função do cansaço. Despertou no meio da noite, no dia subsequente ao ocorrido com a jovem caiapó, com a mesma cena envolvendo a adolescente. Nesse instante, porém, deixaram-na examinar a "enferma". Daniela constatou que a jovem estava sem liberação de esfíncter, sem febre, com semblante assustado, mexendo-se muito. Mais um dia se passou e, com o correr das horas, novo exame, nova conversa com o intérprete e, outra vez, nenhuma resposta. À noite a situação se repetiu pela terceira vez. Passaram-se dois dias e outra adolescente apresentou quadro idêntico. Mais alguns dias e já se contabilizavam "cinco adolescentes com o mesmo sintoma". Daniela começou a formular hipóteses: arbovirose? encefalite? Mas não encontrou algo sustentável. O que a intrigava naquela ocasião era: "por que durante o dia todos estavam bem e não apresentavam nenhum sintoma?".

As noites se repetiam, até que os "sintomas" atingiram alguns homens jovens. "Se para segurar uma moça eram necessários mais ou menos cinco adultos, imagine um homem!", ponderou Daniela. Toda a aldeia estava paralisada.

Fiquei com medo de que eles decidissem fugir todos para o mato. Com certeza eu não conseguiria acompanhá-los. Não dormimos a noite toda e a velha que cuidava de mim me alertou para não chegar muito perto, pois um dos homens 
havia tentado atirar no grupo que o segurava. No dia seguinte, a mesma tentativa de examinar e conversar. Então, o homem da espingarda que falava bem o português me explicou: "na hora a gente não vê os parentes, doutora"; "na hora o que eu vi foi muita coisa feia e eles queriam levar meu espírito, por isso dá vontade de fugir ou atirar".

Foi nesse momento que "lideranças indígenas" disseram à Daniela que pretendiam pedir o auxílio de um pajé de outra etnia. A assistência, parecia significar tal solicitação, não deveria vir de médicos, dispensáveis nesse caso. Enquanto isso a situação de saúde da aldeia se agravava, o que fez a médica interromper o trabalho de tuberculose planejado.

Nesse meio tempo, lideranças indígenas chamaram Daniela. Afirmaram, dessa vez, que a Funai só liberaria recursos para fretar o avião e trazer os pajés necessários para resolver a situação na aldeia se o pedido fosse dela, a médica responsável. A situação era difícil. De um lado, a Funai fornecia apoio com a condição de tirar as decisões das mãos dos Caipó, num misto de desconfiança e autoritarismo. Do outro, Daniela não conseguia desenvolver seu trabalho e via o quadro se complicar, sabendo que seu chefe não aprovaria tal procedimento. Pedir a pajés um auxílio sobre questões de enfermidade poderia ser lido como incompetência, temia a médica. Não obstante o dilema de se encontrar com o dever de mediar dois universos diferentes, com implicações diretas na sua imagem profissional, Daniela escreveu um radiograma para quem liberava o recurso com um discurso nos moldes dos pensados para os altos funcionários da Funai. O texto do radiograma foi descrito da seguinte forma:

Estamos enfrentando uma situação que foge da minha competência e que as lideranças e comunidade definem como doença de índio. A comunidade pede a presença de pajés que, tenho certeza, saberão conduzir o problema e amenizar o sofrimento da aldeia.

Com esse documento, o avião foi liberado. Mas, sem sucesso, pois rusgas antigas impediram a ida dos pajés à aldeia caiapó. A situação se prolongou por mais alguns dias, mas foi controlada localmente. Da mesma forma que surgira abruptamente, assim desaparecera. A única explicação que Daniela recebeu sobre a resolução foi que outros pajés haviam intercedido à distância, e que eles haviam "curado todos". Daniela costuma contar essa história quando instada a falar de seu trabalho em saúde indígena. Quem sabe seja esta uma história, como irei argumentar adiante, que nos conte algo sobre zonas de opacidade e de limites da própria compreensão? 


\section{Carla e a "máquina da vida"}

Carla nasceu em São Paulo, capital, em 1977. Formou-se em enfermagem pela Faculdade do Hospital Albert Einstein. O desejo de infância de ser médica direcionou-se à enfermagem. Essa mudança deveu-se ao "acaso" e à possibilidade que, segundo ela, o curso de enfermagem oferecia: uma maior aproximação com o "cuidar". A propensão juvenil para atuar na área da saúde se somou à curiosidade com "culturas exóticas", curiosidade esta atribuída a "uma insatisfação com o meio urbano".

$\mathrm{Na}$ faculdade, ela se preocupava com o papel social do profissional, pensando em extrapolar a assistência. Os estudos universitários desenvolvidos propiciaram um conteúdo mais voltado para a técnica e com espaço pequeno para os temas de saúde coletiva, de política, de antropologia. As pessoas eram educadas para atuar direta e tecnicamente num ambiente hospitalar. Carla fez estágios nos Hospitais Albert Einstein e Emílio Ribas, o que a levou à certeza de sua inadequação para atuar em hospitais. A ideia era trabalhar com saúde coletiva e "conhecer outras culturas". Começou a procurar instituições como Médicos Sem Fronteiras, Cruz Vermelha, entre outras. Mas foi no Projeto Xingu que se encontrou.

Carla estava fazendo uma capacitação na Unifesp e percebeu um cartaz com as comemorações dos 35 anos do Projeto Xingu. Ela foi ao evento e encontrou os dirigentes do Projeto e lideranças indígenas. Identificou-se com a política de saúde ali proposta. Escutou os indígenas presentes falarem como viam a medicina e discorrerem sobre "a mudança do contato, as doenças, aquela dizimação toda, e atualmente essa mudança do índio querer saber as coisas do branco pra poder se defender, pra poder lutar". A empatia foi imediata, e Carla se deixou "enfeitiçar". "Eu me encantei", repetiu diversas vezes a enfermeira. Esse encantamento conduziu-a ao início de suas atividades no Projeto Xingu. Tudo seria novo para a enfermeira formada no Einstein. Assuntos como "doença de índio, feitiço, xamanismo" eram constantes nas pautas das discussões preparatórias para as atividades de campo.

Apesar dessa preparação, Carla considera sua primeira viagem ao Xingu "dura". Esse primeiro contato é o mais intenso, e é nele que se avaliam as propensões do noviço para o trabalho, colocando-o física e emocionalmente à prova. Na sua autoavaliação, conseguiu se adaptar com facilidade. Mas esses não foram seus maiores problemas, nem a parte mais difícil. Percebeu, à medida que convivia e trabalhava no Xingu, que o mais difícil consistia em aprender a lidar com os próprios valores, como "pessoa ocidental, católica e profissional de saúde". A questão que mais a incomodava era a compati- 
bilização da "história da valorização da vida a todo custo, o salvar a vida a todo custo" com os valores indígenas sobre a vida.

É a tal da velha história de salvar a vida da pessoa. A gente acaba carregando isso. Acho que isso é o que mais a gente tem que trabalhar, porque a gente é formado pra salvar, formado pra que o sopro de vida [permaneça], o coração continue batendo e a pessoa continue respirando. Aquela coisa, quase uma máquina que temos que manter funcionando. Eu lembro de ressuscitar uma criança num barco. Eu estava completamente ensandecida, porque não queria que aquela criança morresse na minha mão. Como se eu tivesse a responsabilidade e todo o poder na minha mão. Isso eu acho que foi o que mais eu precisei trabalhar, trabalhar o tempo todo. Eu não chegava a intervir com as pessoas e dizer "faça isso", "faça aquilo", "não pode". Mas eu sofria por dentro!

Essa vontade de lutar pela vida — "essa máquina de manter funcionando [o corpo humano]" — transformou-se num dos maiores dilemas de Carla. Como lutar pela saúde e pela vida se não se compreende o que é saúde e o que é vida para quem as práticas de saúde são direcionadas? Solicitei a Carla que falasse um pouco mais sobre esse dilema. Ela me contou a história da morte de um bebê.

Uma vez participei de uma história que é bem ilustrativa dos problemas que enfrentamos [os profissionais de saúde] quando trabalhamos com populações indígenas. Foi um processo de luto, numa morte de um bebezinho, muito pequenininho.

Quando Carla chegou à aldeia Tanguro, dos Kalapalo, o bebê deveria ter apenas 15 dias de vida. Naquela época, ela contabilizava somente "seis meses de Xingu". Ao entrar na aldeia, percebeu que todos estavam de luto. Já dentro da oca, notou um choro constante, que associou à dor extrema. Os Kalapalo pranteavam a criança. Só depois entendeu que os pais do bebê eram muito jovens e haviam quebrado uma "regra importante de quarentena". Pelos seus cálculos, o casal teria entre 13 e 14 anos de idade. Não soube exatamente o que havia acontecido, mas ouviu rumores sobre o casal ser jovem demais, sobre atividades interditas, mas realizadas, e que acabaram por desembocar no quadro acima.

Ela soubera da situação pelo agente indígena de saúde. A criança, no diagnóstico de Carla, havia contraído meningite e apresentava a cabeça inchada, febre alta e convulsões. Foi uma cena chocante para Carla. Era a primeira vez que se deparava com morte no Xingu. Ao lado da enfermeira 
colocaram-se três pajés, chamados para acompanhar o velório. O "avô da criança", segundo Carla, "era o cacique", e chorava copiosamente. Ao fundo da cena, uma ladainha das mulheres. A cena foi descrita como bonita e triste: "é uma cena muito bonita assim, triste e forte, todo mundo pintado".

Carla havia chegado no final da tarde e passou a noite acordada, tentando "fazer alguma coisa". Todavia, ela só fazia o que os pajés permitiam: "dava um remedinho pra febre, tentava um sorinho... tentei dar um soro nela, aí perdeu a veia". Um pajé cochichou para o agente indígena de saúde (e Carla pediu para que ele traduzisse): "está vendo como a alma da criança já foi, não adianta a enfermeira querer botar no sangue dela, não tem mais, se ela furar vai sair de novo". Carla, noviça no Xingu que era, ficou desesperada. Não conseguia lidar com a morte daquela criança. Todos na aldeia já estavam de luto, mas Carla percebia "vida" naquela criança e achava que devia "fazer algo". Ela iniciou um diálogo com os pajés sobre o assunto, indagando sempre sobre a possibilidade de intervenção.

Eu fui ao pajé considerado assistente. Cheguei nele devagarzinho assim e disse pra ele o que eu pensava daquela doença e da possibilidade que eu podia oferecer da criança ir logo cedo pro posto. Lá havia um médico, e de lá eu podia pedir um avião pra aquela criança ir direto pra cidade. Ele olhou pra mim assim com uma cara de, tipo assim, fora de cogitação. Assim: “Não. Deixa pra lá, você já fez o seu trabalho. Este aqui - e botou a mão no peito - este aqui não tem mais alma, falou outro nome lá, espírito, ó, foi, acabou, morreu". Imagina se eu entendi aquilo. Falei: "não, pajé, mas olha, veja, o nenezinho, está vendo ó, está respirando. Olha aqui, eu posso levar, tem médico no posto, tem médico". E ele disse: "não vai minha filha, você vai perder tempo".

Carla não se conformou. Passou a noite em trabalho de convencimento. Percorreu o que classificou de "hierarquia dos pajés". Chegou ao pajé que considerou de maior prestígio. Demorou a conseguir falar com ele. Quando finalmente se aproximou, com toda a deferência, contou sua versão, argumentando que havia vida naquela criança. Ao que o pajé retrucou: "Minha filha, está bom. Você já trabalhou (rindo). Agora não dá mais, pode descansar, vai dormir, amanhã você trabalha, vê outro, outro, outro. Esse aqui não, que este já foi. Menina [apontou para mãe da criança enferma], menina ainda não sabe ter filho. Mamaé levou embora".

A conversa sobre o tema com o primeiro pajé foi realizada com o auxílio do agente indígena de saúde, que traduzia para a língua nativa o que Carla perguntava e, na sequência, traduzia as formulações do pajé. 
Posteriormente, a enfermeira passou a estabelecer conversações em português, em frases bem resumidas e sempre perguntando. "Por que a criança morre?"; "Por que não posso tentar salvá-la?". As respostas, também em português, insistiam em que a criança não tinha vida, que o "espírito" havia partido: "Mamaé levou embora". O quadro poderia ser telegraficamente caracterizado da seguinte forma: traduções entre línguas; busca sistemática de comunicação; interlocuções difíceis, auxiliada por gestos e expressões; gramáticas culturais diferentes em conexão.

A imagem impressionava Carla: os dois meninos - o casal de pais do pequeno enfermo - de cabeça baixa, a ladainha, as pinturas corporais, o choro insistente, a paciência dos pajés, o bebê de cabeça inchada, febril e com convulsões. Ela não se conteve e pela manhã procurou o avô da criança. Tanto fez que conseguiu convencê-lo a levar o doente ao Polo Base, o Posto de Saúde Leonardo. No barco surge outra imagem que Carla jamais esqueceu: o avô dirigindo o barco a motor, chorando; a mãe com o bebê no colo, ao lado de Carla; o pajé sentado na proa. Este, de meia em meia hora, virava-se para a enfermeira e perguntava: "e aí, minha filha, já morreu?". E Carla retrucava: "não, ainda não". Carla olhava o bebê, que já estava entrando num processo de morte cerebral, contorcendo-se, virando o braço. Mais meia hora e o pajé se virou e perguntou com naturalidade: "então, minha filha, já morreu?". Carla, o avô e a mãe da criança choravam.

O barco descia o rio Kuleune. Estavam na época de seca e é sempre perigoso conduzir a embarcação nesse período. Após três horas nas grandes águas do rio Kuluene, o barco teve que serpentear pelos tortuosos igarapés do Tuatuari, estreito e cheio de curvas. Seria mais uma hora nos labirintos do igarapé, mas o avô, que conduzia o barco, perdeu-se, atrasando a viagem. Ainda nos igarapés, faltando pouco para chegar ao posto de saúde Leonardo Villas Bôas, o pajé voltou-se e repetiu a pergunta: "e aí, minha filha, já morreu?". Carla então respondeu: "não, mas vai morrer, vai morrer. O senhor estava certo". A criança morreu ali, antes de chegar ao posto, no centro sinuoso do Tuatuari.

Cheguei no posto e desabei! Desabei tanto por ter vivenciado aquela morte como por ter vivenciado aquela morte no lugar errado, do jeito errado. E aí eu me acabei de chorar por ter tirado ela [a criança] do processo mais importante pra ela naquele momento. Era a coisa mais importante pra ela e pra família dela: morrer dentro da casa dela, com aquele luto, com aquela cena bonita, com aquela coisa toda do povo dela, e não num barco, correndo. Enfim, naquele momento eu percebi que só eu não tinha me dado conta. Não tinha entendido. Só eu não me conformava com a morte. 
Carla ainda atua no Projeto Xingu. Essa história vem servindo para orientar sua conduta com comunidades indígenas. Em situações semelhantes, como veremos mais à frente, a enfermeira teve atitude diferente.

\section{Limitações, limites e práticas de tradução}

Neste artigo acabei por me concentrar nas narrativas de Daniela e Carla porque, além da maior proximidade estabelecida no transcorrer da pesquisa, elas deixam claros alguns motivos (Deleuze 1997) que se repetem, frequentes na composição geral da forma de perceber a intervenção e de lidar com concepções de saúde diferenciadas.

Nas narrativas de Daniela e Carla, a escolha pela profissão deu-se segundo o desígnio de "fazer algo para mudar a sociedade". Daniela descreve imagens de sua infância nas quais a temática indígena aparece sempre vinculada à situação de vulnerabilidade. Ser médica surge como opção de intervenção em "populações necessitadas". Carla manifesta-se crítica das relações no "meio urbano" e busca na profissão uma "forma de cuidar". Em ambas, às imagens das "populações indígenas" — consideradas "vulneráveis", necessitando de ações que possam amenizar os problemas e a penúria - soma-se a ideia da biomedicina como instrumento eficaz de intervenção. Medicina e enfermagem são compreendidas como meios disciplinares que possibilitam agir. Não há como se desviar aqui da relação direta entre vulnerabilidade e salvação, entre "crenças" indígenas e uma soteriologia racionalizada de uma salvação técnica; nem como se esquivar da percepção da profissão como lócus de batalha entre "populações" que sofrem e profissionais que cuidam - a profissão idealizada como um combate apaixonado em nome dos que sofrem. Esse tom soteriológico configura-se em motivo habitual nas narrativas dos profissionais de saúde com os quais mantive contato (Good 1994; Fóller 2004:134). Todavia, minhas pesquisas indicam que acontece alguma coisa no meio do caminho que provoca uma torção nas narrativas, assinalando a existência de outros motivos.

Essa torção pode ser observada no movimento das próprias narrativas, que vão de um discurso de "salvação médica de populações vulneráveis" a outros que abordam as limitações da biomedicina. Estamos diante de discursos que realçam as limitações e apresentam situações em alguma medida refratárias às intervenções dos profissionais de saúde. Talvez Daniela seja a mais incisiva em mostrar uma história da limitação. Ela fala de zonas obscuras nas quais seus saberes são incapazes de alçar aos saberes indígenas. Os limites de sua ação indicam que não há uma equação na qual médico 
e biomedicina são igualados. Sua atuação não se circunscreve aos ditames de uma ciência que supostamente englobaria toda a sua ação. A linguagem de Daniela permanece tributária do vocabulário composto por termos como "crença" e "intervenção", mas nem a descrição de crenças nem a potência da intervenção se destacam em sua narrativa, que aborda a incapacidade de intervir ou uma ação que só obtém algum êxito descolando-se da biomedicina. No caso de Daniela, o médico atua em face do enfermo sancionado pela ciência, mas a atuação não se ancora na ciência.

Carla fala de si como alguém profundamente abalada pela resistência de outro tipo de concepção de vida. Ressente-se pela ação de uma "máquina da vida" que aprendera com seu ofício, mas que, ao mesmo tempo em que a impele a agir, obsta a capacidade de perceber outras formas de vida. Quando estimulada a discorrer sobre sua profissão, é com um "equívoco" que resolve exemplificar. ${ }^{5} \mathrm{O}$ seu limite, portanto, se localiza naquilo que acreditava ser a potência de sua intervenção. É a "máquina da vida" que sua história dilacera. Sua narrativa indica que o limite da atuação deve se pautar na radical diferença sobre a concepção da própria vida. Aquele bebê e todo o funeral kalapalo sugerem a existência de percepção sobre vida e enfermidade que Carla não conseguiu entender. Foi preciso se aventurar pelo rio Kuluene e se adentrar nos igarapés do Tuatuari para enfim compreender seu próprio limite de compreensão. Esse espaço de passagem, esse limbo no qual se meteu com o avô da criança - um pajé que insistia no que já sabia desde o início daquela história - e a tímida mãe do bebê, foi revelando a ela algo impressionante: todo mundo já sabia o que iria acontecer, exceto ela. Sua incapacidade de escutar o que diziam os pajés na noite anterior à descida do rio assinala os limites da atuação de profissionais de saúde em comunidades indígenas.

Por mais de dois anos venho escutando médicos e enfermeiros que trabalharam com saúde indígena, principalmente os vinculados ao Projeto Xingu. Essa experiência me colocou diante de múltiplas histórias de limitação. Por exemplo: num encontro casual com profissionais envolvidos com saúde indígena não se tardou a mencionar a história de um médico que se transformara num dos melhores especialistas de sua área. Num dia no Xingu, tal médico se deparou com um caso de "feitiçaria". Com uma reputação nacional, que ele considerou em jogo naquela ocasião, prontificou-se a acompanhar o paciente indígena. Não parecia segredo para ninguém que, na concepção desse médico, ali se debatiam "ciência" e "crenças locais" (só por condescendência, não denominada de superstição). Depois de três dias de vigília, o índio faleceu, sem que a intervenção surtisse efeitos e sem qualquer explicação plausível do ponto de vista biomédico. Não importa 
que a história seja verdadeira ou que não tenha ocorrido tal qual me contaram, até porque está envolta num tom de mistério e é sempre contada numa generalidade das histórias exemplares. E como história exemplar, e é isto que me interessa mais particularmente, findava sempre com a seguinte exclamação: "isso acontece com todos nós!". Tudo se passa como se, para falar sobre a potência de sua intervenção, fosse necessário apresentar os limites do empreendimento, e assinalar seus equívocos.

Estranhos profissionais estes que, quando instados a falar sobre seu ofício, acabam por discorrer não sobre seu alcance e sua potência, mas sobre seus limites. Daniela não consegue compreender nem intervir nos casos de "convulsão" dos Caiapó. Sequer soube o que havia acontecido ou como foi resolvido. Apenas repete, sem compreender, a história da intervenção de outros pajés que teriam solucionado os distúrbios na aldeia. Sua busca para identificar a enfermidade revelou-se inócua. Embrenhada numa cosmopolítica ameríndia, na qual o medo dos "espíritos", somado a manifestações corporais identificadas (mal traduzidas) como convulsões, em meio a rituais de cura, conflitos entre etnias, presença de garimpeiros, a médica que sonhava com índios antes da medicina e pensava a medicina como forma de ação - descobre a fragilidade tanto para compreender como para encontrar equivalência em sua gramática cultural. Chegou a um ponto em que a medicina a abandonou.

Carla, por sua vez, deparou-se com novas formas de vida. A enfermeira, crítica das relações urbanas, que projetava seu ofício como forma nobre de cuidar, aprende com os Kalapalo os limites de sua própria condição de compreender e os efeitos pouco nobres que o cuidar pode tomar.

Qual a razão de Daniela e Carla terem narrado justamente aqueles episódios nos quais suas formações profissionais não as puderam ajudar? $\mathrm{Ou}$, mais diretamente, por que selecionar num universo tão grande de experiências com a alteridade (que incluem práticas educativas, controle de epidemias, crescimento populacional do Parque do Xingu etc.) exatamente os pontos que não conseguiram ultrapassar? E qual o motivo de eleger histórias exemplares de atuação em saúde indígena selecionando experiências que sequer entenderam?

Para tentar responder a essas indagações talvez seja necessário ampliar o conceito de limite. Há a possibilidade de compreender limite como linde ou limiar, como algo que acontece entre dois universos e como aquilo que ocorre entre dois mundos. Nesse sentido, limite implica processos de tradução entre universos. E este é o terceiro motivo das narrativas: a tradução. A atuação da médica e da enfermeira está centrada numa busca de traduzir concepções, palavras, ações. ${ }^{6} \mathrm{O}$ paradoxal da intervenção desses personagens é que ela 
só consegue se efetivar num relativo afastar-se da biomedicina. Esses profissionais são chamados a atuar em nome de um conjunto de concepções e tecnologias (a biomedicina), mas suas ações só podem se efetivar se mantiverem distância relativa que permita processos de tradução.

A questão não é, portanto, só a dificuldade de estabelecer conversações, embora seja também aspecto pungente nas experiências vivenciadas: Carla fala com a ajuda de tradutores, especialmente agentes indígenas de saúde, e com pajés que dominam apenas algumas frases em português; Daniela está na mesma situação e necessita de auxílio de tradutores para compreender o quadro. Porém, a conjuntura seria mais bem caracterizada se pensássemos em imaginações conceituais, convenções, formas de percepção de saúde e doença em contato. A médica procura na sua gramática cultural, no seu vocabulário, detectar doenças, interpretando determinadas experiências corporais dentro do quadro nosológico biomédico. A classificação apresentada pelos Caiapó como "doença de índio" é, nesse caso, uma tentativa caiapó de traduzir suas próprias concepções dentro de um léxico mais ou menos compreendido pela médica, um tipo de comunicação instrumental. Estavam em jogo ali formas diferenciadas de percepção de corpo e doença, além de terapêuticas distintas, numa linguagem possível. Para Carla, o que estava em jogo naquela zona limite entre concepções diferenciadas de vida era o próprio conceito de vida. Os complexos conceitos kalapalo de corpo, a linguagem dos rituais (dos quais Carla só conseguiu perceber a beleza e a solenidade), as percepções e as relações entre vida e morte constituíram-se numa experiência pouco compreendida e mal traduzida, mas que interpelou a enfermeira a ponto de ela perceber sua não percepção.

Tanto o idioma quanto o vocabulário técnico fornecido pela biomedicina não operaram a contento naquelas situações. Termos como "epilepsia", "convulsão", "ataques" foram tentativas dúbias de tradução. As expressões utilizadas nas narrativas da enfermeira e da médica já são produtos de processos de tradução: "pajés", "chefe", "pai", "mãe", "avô". Configurações de parentesco, instituições, sensações foram imediatamente transcritas para a realidade dos profissionais de saúde. Entretanto, as traduções se revelaram equívocas.

Há muito que se reconhece a impossibilidade de uma tradução integral. Persiste nos processos de tradução, argumenta-se, algo de intraduzível; persistência que evoca termos como "indecibilidade", "resto", "equivocacidade", donde a máxima italiana traduttore traitore. E se traduzir é trair, afirma Viveiros de Castro (2009:54), uma boa tradução seria aquela que trai a língua de chegada e não a de partida. Uma boa tradução consegue fazer com que os conceitos estrangeiros subvertam os dispositivos conceituais do tradutor. Algo subsiste de intraduzível que interpela os tradutores, existindo 
a possibilidade (e o risco) de os processos de tradução seguirem o fluxo: tradução, traição, transformação. A agência da estrangeiridade, no trabalhar contínuo das traduções, pode provocar transformações nos conceitos, nas perspectivas e nas formas de percepção. Contudo, o processo de tradução não é algo apenas conceitual.

Conceito, para Deleuze (2007:171), comporta duas outras dimensões, as do afeto e do percepto, indispensáveis para o movimento, para o devir. Apesar de conceito ser "algo diferente", não tem "nem sentido nem necessidade sem um 'afeto' e um 'percepto' correspondentes" (Zourabichvili 2004:4). Se as traduções mobilizam as "outras dimensões" do conceito, podem alterar os afetos e os perceptos. E, ainda que não abalem totalmente esse "algo diferente" que é conceito, podem implicar profundo movimentar de afetos e perceptos. O que estou tentando argumentar aqui é que esse processo complexo de limitações e limites, de equívocos e necessárias e incompletas traduções (que deslizam de simples traduções linguísticas a zonas de incomensurabilidade) pode afetar os profissionais de saúde.

O limite é instância do devir incessante de sentido e de sua suspensão, local de passagem e de conflitos, de afirmações e reafirmações de sentidos prévios, e de hesitações constantes (Fóller 2004). O profissional de saúde, pressionado pela urgência da tradução, por Outros que se lhe impõem como condição mesma de realizar aquilo que acredita ser seu ofício, atormentado por sua própria linguagem e por seus próprios textos, dos quais não consegue se despregar facilmente, e com os quais tem que trabalhar para conferir sentido às experiências, não encontrando equivalentes, e muitas vezes despreparado para esse encontro e essas traduções, ora é levado a traduções etnocêntricas - aquela tradução que nega a estranheza da obra estrangeira (cf. Berman 2002:18) — ora é afetado pelo Outro - deixando-se levar, nesse caso, por esses encontros, alterando-se, modificando o próprio sentido dos encontros. Surgem nesses encontros imprevisíveis ocasiões em que a biomedicina já não é mais suficiente, como vimos nos casos narrados por Daniela e Carla. Essa insuficiência - na qual o profissional de saúde é parcialmente privado daquilo que seria, em tese, sua estrutura de pensar - possibilita que esses encontros produzam mais do que uma tradução etnocêntrica.

É certo que, nesses encontros, profissionais de saúde vêm produzindo sistematicamente traduções etnocêntricas, como muito já se alertou. Todavia, na experiência com a alteridade, não se pode controlar tudo; e as histórias de Daniela e Carla apontam para essa instabilidade: algo afeta os profissionais que se veem na presença de um Isto sem nome, sem precedentes no vocabulário e na sintaxe; um Isto que se impõe no momento da atuação. 
Acaba aqui a suficiência que diz: "na biomedicina, Isto seria explicado de tal forma", deixando de funcionar a simples evocação: "em minha língua Isto se diria assim" (Moraes 2008:234). Não encontrando traduções equivalentes familiares, pois o repertório conceitual "deles" não pode ser revelado como isomórfico em relação ao "nosso" (Holbraad 2003:43), aparecem então as hesitações, os equívocos, o gaguejar, as limitações que afetam os profissionais de saúde. Trata-se aqui, portanto, de pensar os afetos dos processos de tradução naquilo que possibilitam, nas torções que provocam.

\section{Afetos e afecções}

Foi assinalando um problema de tradução que Deleuze (1978), num de seus cursos em Vicennes, iniciou sua leitura de Espinosa. Deleuze alertava para a "catástrofe" de traduzir affectio e affectus para afecção, lembrando que em francês há os termos affect (afeto) e affection (afecção), mais próximos da forma utilizada por Espinosa. ${ }^{7}$ Há uma distinção entre afeto e afecção que o emprego de um só termo acaba por olvidar.

Afeto estaria relacionado ao efeito de um corpo sobre outro, um corpo sofrendo ações de outro. Afecção seria uma mistura de dois corpos, um corpo que age sobre outro, que por sua vez recolhe traços do primeiro. Affectio assinala um estado do corpo afetado, implicando presença do corpo afetante; affectus indica a passagem de um estado a outro, tendo em conta a variação correlativa dos corpos afetantes. Cada afecção é como uma interrupção na continuidade da potência de um modo, tal como o que se produz em nós a partir de um encontro que aumenta ou diminui nossa força de existir. O afeto não se reduz a uma comparação intelectual das ideias, é antes constituído pela transição vivida ou pela passagem vivida de um grau de perfeição a outro. A afecção, definida como uma mistura de corpos, indica a natureza do corpo modificado, a natureza do corpo afeccionado e afetado.

Afetos também não são sentimentos, são forças que nos atravessam, ultrapassando a distinção entre sujeito e objeto, já que o homem se transforma noutra coisa em virtude de uma fusão, de um entrelaçamento. Afetos são devires não humanos do homem; e devires são encontros, indiferenciações; trata-se, portanto, de uma zona de indeterminação, de indiscernibilidade, como se coisas, animais e pessoas atingissem um ponto (embora no infinito) que precede imediatamente sua diferenciação. Afetos não são, ainda, interiores: estão no interstício, no entre, nas intercessões; são vibrações ou intensidades e, por isso, não se confundem com o que é vivido numa interioridade subjetiva. Sentimento só pode ser percebido a partir da dimensão 
afetiva, construído por múltiplos laços e encontros, mas unificados numa significação. De forma que sentimento é aquilo que move, e o afeto é o próprio movimento, num contínuo diferir.

Para resumir: as afecções, embora aconteçam de uma só vez, são efeitos de um corpo sobre outro no espaço; os afetos são os efeitos de um determinado corpo sobre uma duração — variações de potência. Afeto corresponde, portanto, ao modo como problematizamos nossas afecções, nossas dores e prazeres; afecção é tudo aquilo que o corpo absorve no encontro com outros corpos.

Essa discussão sobre afetos e afecções está, por conseguinte, relacionada aos limites e aos processos de tradução, ao interstício, aos encontros (bons e maus). A indagação que venho apresentando é em que medida essas experiências (essas misturas, essas afecções) com a alteridade radical, como as narradas por Daniela e Carla, possibilitam um afetar-se, permitem um devir outro. Esses profissionais de saúde podem ser afetados? De que maneira? Qual a possibilidade de uma atitude de escuta do outro? Para prosseguir nessa reflexão podemos, por um instante, colocar as experiências de Daniela e Carla sobreimpressas (Almeida 2007) às comumente associadas à biomedicina.

As verdades e os conceitos da biomedicina possuem força normativa que incide diretamente sobre as convicções e os estilos de vida das pessoas. A medicina lida com períodos cruciais, como vida, morte, nascimento, enfermidade, impondo-se como definidora das formas ponderadas de bem viver. As narrativas médicas geralmente operam da seguinte maneira: supõe-se um consenso da saúde como valor fundamental e primário e que as enfermidades são nocivas e devem ser "combatidas", desejando delas todos escaparem; localizam-se, imediatamente, determinadas condutas como condições originárias das doenças e, assim, conclui-se que essas condutas devem ser evitadas, combatidas ou extintas. Não é necessário muito para se detectar nos discursos biomédicos essas pretensões normativas, que se estendem por múltiplos campos - dietética, sexualidade, higiene, terapêutica. Os pesquisadores da área vêm alertando para a dimensão normativa e prescritiva das narrativas dos profissionais de saúde, sustentando que na biomedicina etiologia e normatização andam juntas, e que o poder normativo da biomedicina cresce com seus êxitos e sua eficácia como tecnologia. Como ciência do normal e do patológico, a biomedicina torna-se dominante entre as ciências, estabelecendo os padrões de razoabilidade dos comportamentos (Canguilhem 1984).

O encontro de profissionais de saúde e comunidades indígenas coloca a força das narrativas biomédicas, com seu poder e sua eficácia, ao lado de outras formas de perceber saúde e doença, além de outras terapêuticas, proporcionando conflitos e disjunções já bastante e apropriadamente comentados (Langdon 2001; Fóller 2004). Nesse encontro, as relações entre 
profissionais de saúde e índios são eminentemente hierarquizadas, pois colocam no polo valorado a biomedicina e os saberes ocidentais e, no polo desvalorizado, os saberes indígenas, considerados como manifestação do desconhecimento e da ignorância, ou como crenças ineficazes. Quem trabalha na área percebe amiúde profissionais de saúde classificando índios de ignorantes sobre saúde e doença; pacientes indígenas que não "acatam" as medidas terapêuticas propostas são denominados de desobedientes. As histórias de Daniela e Carla, contudo, nos contam algo mais. Os motivos que compõem as narrativas de Daniela e Carla em suas experiências em saúde indígena demonstram um afetar. Daniela e Carla se direcionam, lentamente, para uma distância relativa de um tipo de saber. Seja verificando seus limites, seja questionando a própria "máquina da vida", esses encontros, essas afecções, alteram a potência de agir desses profissionais de saúde que, antes de se anularem diante do saber biomédico, acabam por se mobilizar.

De alguma forma, narrativas que poderiam se voltar para a potência da intervenção (daqueles que mudam quadros epidemiológicos), para seu caráter heroico e exitoso (daqueles que trazem soluções técnicas e terapêuticas para salvar "vulneráveis"), ou "humanitário" (daqueles que buscam salvar vidas), acabam por se centrar nos equívocos e nas dificuldades. Essa torção produz - e é produto de - novas subjetividades e novas formas de olhar. Dito diretamente: limitações, limites e processos de tradução não só dizem algo sobre os profissionais, como podem ser simultaneamente produtos e produtores performáticos de novas formas de agir e pensar a saúde indígena. A experiência contínua e persistente em processos de tradução nessa zona de intermedicalidade, como aqui descrita, pode implicar esse afetar.

Afetos e afecções vão além do reconhecimento dos limites e das dificuldades de tradução - o que por si já é uma torção daquela força normativa da biomedicina, como já abordado. Algo se transformou com as experiências vividas. O contato com formas diferenciadas de perceber saúde e doença, a necessidade da tradução para poder atuar e os limites das ações alteram as práticas posteriores de Daniela e Carla. Esta última nos conta um episódio que resume bem o que venho argumentando:

Aconteceu outra situação. Tínhamos uma criança ikpeng num hospital local com uma doença congênita. Sabíamos que, se ela fosse encaminhada a Brasília, poderia sobreviver fazendo uma cirurgia. Mas os pajés pediram pra voltar pra aldeia. Aí, neste caso, eu estava na cidade, trabalhando neste meio de campo entre aldeia e hospitais da região. Isso aconteceu quando eu tinha mais tempo de Xingu. Os pajés pediram para esta criança voltar. O pai decidiu. Eu esclareci minha posição. Disse pra ele que a criança poderia morrer. E a criança morreu lá na aldeia. 
Dessa vez Carla, que já havia experienciado aquele dramático encontro com os Kalapalo, agiu de forma diferente. Algo daquele encontro se incorporou na enfermeira, algo daquela afecção restou. Acompanhemos um pouco mais o desenrolar de sua história:

O mais curioso foi lidar com a raiva, com a indignação do médico que trabalhava no hospital, que tinha indicado a criança pra Brasília. Ele me olhou, depois que eu disse pra ele que a família tinha decidido que a criança ia voltar e que não ia ter mais negociação. Disse que a gente já tinha esclarecido, tinha colocado tudo na mesa e que eles falaram: "não, se for pra morrer, vai morrer lá na aldeia!". Aí, ele [o médico da cidade] falou com zombaria assim: "é impressionante como em pleno século XXI vocês ainda dão corda pra essas crendices! Essa criança vai morrer!". E eu falei: "pois é, pelo menos que morra no lugar dela, na terra dela, com o povo dela, do que morrer num corredor de hospital". E é isso!

Entre o rio Tanguro e o hospital algo mudou. O afeto é essa modificação. O afetar pode indicar que talvez os exercícios e as práticas dos profissionais de saúde possam ser compreendidos para além daquele quadro de reificação descrito por Taussig, ou para além das malhas de um poder em que tudo é controle por parte da biomedicina e dos profissionais de saúde. Por mais precários que sejam esses encontros, há a possibilidade de se insinuarem afecções e afetos que mudam a potência de agir.

De forma similar ao acontecido com Carla, algo daquele encontro com os Caiapó - dos corpos agitados, das manifestações corporais que questionaram a biomedicina - restou em Daniela. A médica atualmente trabalha com os Guarani de São Paulo. Na última vez em que conversamos sobre o assunto, estava preocupada com a "violência contra a mulher", que vem se tornando prática recorrente entre os Guarani. De início, a médica vinculou violência à "pobreza daquela população". Em seguida, seu discurso passou a colocar indagações sobre as especificidades de gênero, sobre como entender a violência contextualizando-a e sobre as dificuldades de uma atuação sem conhecimento das especificidades. Suas indagações terminam por solicitar auxílio de antropólogos para compreender aquele quadro: "É que ficamos sozinhos! Se pudéssemos pensar juntos, iríamos mais longe, cometeríamos menos erros". Talvez os Caiapó tenham lhe ensinado exatamente isso: os limites do conhecimento próprio e a necessidade de abertura a saberes outros.

Esse quadro permite ainda algumas perguntas. Podemos nos questionar até que ponto esse afetar incidiria sobre o próprio saber biomédico, transformando-o. Se nessas experiências narradas, Daniela e Carla tiveram que 
se afastar da biomedicina para alçar minimamente outros saberes, podemos então interrogar: como esses outros saberes, afecções e afetos interrogariam a própria biomedicina? E, assim, pensando nalgum ponto no futuro, será que a saúde indígena poderá transformar o próprio fazer biomédico e a forma de conceber e organizar a assistência à saúde no Brasil? Evidentemente, não tenho condições de responder a estas indagações. Mas, de qualquer forma, uma abordagem que apenas caracterize os profissionais de saúde como meros implementadores da reificação desconsidera as fissuras e as disjunções características das experiências narradas neste texto. E nos leva a refletir sobre uma antropologia dos afetos.

\section{Notas finais}

A bibliografia sobre saúde indígena no Brasil vem apontando, por diversos caminhos, as dificuldades enfrentadas e os limites do encontro entre profissionais de saúde e comunidades indígenas, mas também vem indicando as possibilidades de comunicação (Langdon 1991, 2001, 2004, 2005; Fóller 2004). As análises se voltam para as concepções de saúde, doença e terapêuticas indígenas (Lagdon 2001, 2004, 2005); para perceber como as sociedades indígenas constroem o contato (Buchillet 1991; Garnelo 2003; Garnelo \& Wright 2001; Perez Gil 2007); para quadros de intermedicalidade (Fóller 2004). O contexto geral de intermedicalidade aponta mesmo para a convivência de sistemas médicos distintos, originando sistemas médicos híbridos - um espaço de medicinas híbridas onde os agentes interagem na prática e na teoria. Como dito anteriormente, não raro a interação ocorre numa conjuntura de conflitos, na qual os conhecimentos indígenas são considerados menos valiosos que a biomedicina e concebidos como obstáculo ao "desenvolvimento". Neste caso, a biomedicina é percebida como ativadora de uma etnomedicina destituída de sua própria agência.

As análises supracitadas, não obstante, sustentam que os povos indígenas estão longe da passividade; ao contrário, num quadro de simultaneidade de tradições epistemológicas, incorporam artefatos e ideias e exercem agência social, construindo algo novo. O conhecimento indígena é dinâmico, criativo e sujeito às influências, perfazendo negociações e renegociações constantes entre as diferentes formas de saber médico. O que busquei sublinhar aqui é que a agência indígena e os encontros em situações de intermedicalidade, como as descritas neste artigo, podem propiciar que os profissionais de saúde sejam também eles afetados no próprio processo de (re)negociação e tradução que a intermedicalidade enseja. 
Num quadro como este, a simples crítica à objetividade médica, à diferença de linguagem entre profissionais de saúde e pacientes, ao exercício do poder médico não consegue - parecem dizer as experiências aqui analisadas abarcar todas as dimensões nas quais profissionais de saúde se relacionam com cosmopolíticas ameríndias. Mesmo para contextos urbanos e médicohospitalares, essa crítica forma um quadro estático e geral demais para dar conta daquilo que se passa nos dramas sociais que são as enfermidades. Levar a sério a possibilidade de os profissionais de saúde serem afetados em situações de alteridade radical é uma tentativa de pensá-los como agentes sociais, como seres históricos, capazes de serem afetados pelo outro.

Um enfoque exclusivo nas relações de poder ou nos processos de reificação acaba por impedir uma aproximação com a complexidade da própria experiência vivenciada. Admitir que a experiência com alteridade radical nada provoca em profissionais de saúde - principalmente aqueles por um período razoável de tempo interpelados por diferentes concepções de saúde, de doença e de terapêuticas, e que só podem atuar em processos de tradução, como nos casos de intermedicalidade - seria atribuir um poder desmesurável à biomedicina, além de uma homogeneidade aos sujeitos e, sobretudo, uma extrema debilidade indígena. Se acolhermos esta hipótese, a imagem seria mais ou menos esta: dois blocos homogêneos, um empoderado e com potência para agir e transformar o outro — ainda que seja idêntico a si mesmo do início ao fim; outro, receptor, em perigo, em necessidade, vulnerável, sem qualquer capacidade de interação e sem afetar o outro, e igualmente sempre idêntico a si.

Nos dois casos, blocos anistóricos. Todavia, se os contextos de intermedicalidade demonstram como as comunidades indígenas são extremamente criativas na negociação com a biomedicina, e se, como vimos, esses contextos são caracterizados por complexos processos de traduções - que expõem também a sensibilidade do profissional de saúde às dificuldades e às armadilhas das passagens entre códigos que não são inteiramente equivalentes (Carneiro da Cunha 1998:14) — não me parece estranho aventar a probabilidade de essas formas criativas de pensar e agir e os processos de tradução afetarem os profissionais de saúde. Daí a necessidade de se afastar de uma postura que homogeiniza a variedade de pessoas, desenha suas estratégias como meros exercícios de poder e controle, privilegiando apenas a vinculação com a biomedicina (considerada também como discurso homogêneo), ignorando-se a complexidade e a historicidade dos agentes.

Este artigo tentou seguir um caminho diferente, argumentando na direção de uma antropologia dos afetos ${ }^{8}$ - uma antropologia que possa ir além da reificação e do poder. Se as relações podem capturar e assujeitar 
pessoas, inserindo-as em mecanismos de controle e coerção, os afetos podem também mostrar disjunções, hesitações, lapsos e movimentar devires centrados em - para falar como Espinosa (2007), usando expressão cara a Deleuze (1968; ver Sévérac 2005 e Hardt 1996) — "alegrias ativas". Em vez de uma focalização exclusiva em campos rígidos e reificados, uma antropologia dos afetos que permita assinalar algo das realidades que fluem e escapam, compostas por linhas de fuga, e que se volte para subjetividades que excedem, resistem e esquivam (Deleuze 1986), não se configurando exclusivamente como instâncias reificadoras. Uma antropologia dos afetos que ocorrem nesses encontros complexos - com todos os seus limites, traduções, hesitações.

Recebido em $01^{\circ}$ de abril de 2012

Aprovado em 27 de novembro de 2012

Pedro Paulo Gomes Pereira é professor da Universidade Federal de São Paulo. E-mail: < pedro.paulo@unifesp.br>

\section{Notas}

${ }^{1}$ Taussig (1992) procura demonstrar que, como ser social total, a reificação e a alienação atingem os fenômenos de enfermidade. A objetividade ilusória (Lukács 1974) conduz à apropriação dos corpos dos doentes como se fossem coisas, como se fossem realidade exclusivamente físico-biológica. As práticas médicas tornam-se exemplos do processo de reificação e de agência das consciências reificadas, produzindo um homem alienado de si (de seu corpo e de sua doença) e dos outros homens.

${ }^{2}$ Nesse artigo, Taussig (1992) se refere à realidade médico-hospitalar. Mas, mesmo noutros trabalhos, como em sua análise do terror e cura em Putumayo (Taussig 1993), os profissionais de saúde aparecem apenas como operadores do processo de reificação (1993:273-279): médicos que prescreviam receitas de fármacos extremamente caros para miseráveis, que logo voltavam à água poluída e à falta de comida; medicamentos produzidos por multinacionais qualificadas de "abutres que se alimentam de lixo e tripas" (1993:273). Existe uma persistência na forma de descrever os profissionais de saúde, pois a narrativa de Taussig sequer insinua a existência de dilemas, dificuldades, limites ou ambiguidades nesses personagens, sempre vinculados ao poder e a atitudes autoritárias. 
${ }^{3}$ Optei por utilizar nomes fictícios.

${ }^{4}$ Sobre as categorias "doença de índio" e "doença de branco", ver Gallois (1991) e Barcelos Neto (2006).

${ }^{5}$ A afirmação dos limites de atuação do profissional que lida com saúde indígena era diretamente proporcional ao "tempo de campo". Quando iniciante, com pouco tempo em áreas indígenas, o profissional tende a enfatizar as ações diretas realizadas, e a conversa gira em torno dos aspectos biomédicos. Todavia, quanto mais experiente, mais os aspectos se voltam para o que venho denominando de "limites": o que não se consegue implementar, o que não se compreende, os equívocos, o incomensurável.

${ }^{6}$ Tradução é geralmente entendida como a interpretação do significado de um texto numa linguagem específica, e a produção noutra língua de um texto equivalente que comunica a mesma mensagem. Tradução é, assim, uma busca de compreensão de sentidos por meio de tentativas de aproximações de línguas, mas também de diversas esferas, instâncias e modos de pensamento. Neste texto, além dessa acepção geral, estão em jogo as regras e as convenções de cada tipo de linguagem, em suas especificidades culturais. Como a moderna teoria da tradução vem apontando, os agentes de tradução não são neutros. Ao contrário, interferem no processo de tradução, criando no mesmo ato que simulam reproduzir, ou melhor, inventam simulando reproduzir. Sobre o tema existe uma bibliografia considerável: Asad (1986), Tambiah (1995), Latour (1989, 1997), Benjamin (2001), Derrida (2003, 2005), Ricoeur (2004), para citar algumas das mais destacadas contribuições. Importantes para este artigo são os seguintes trabalhos, presentes na composição geral de meu argumento mesmo quando não citados diretamente: Berman (1995, 2002, 2007), Goldman (1999), Carneiro da Cunha (1998), Albert (2002), Albert e Kopenawa (2010), Viveiros de Castro (2000, 2004, 2009). Sobre tradução em Deleuze, ver Burchill (2007).

${ }^{7}$ A discussão sobre os conceitos de afeto e afecção é central na composição geral da filosofia de Deleuze, perpassando boa parte de sua obra (1978, 1987, 1992, 1995, 1997). Busquei apenas pincelar o assunto.

${ }^{8}$ Sem condições de abordar mais detidamente o assunto, apenas apresento, muito sumária e despretensiosamente, a ideia de uma antropologia dos afetos, com a aspiração de desenvolver a discussão noutro lugar. Se sentimento é aquilo que move e o afeto é o próprio movimento, como sustenta Deleuze, só em parte uma antropologia dos afetos se aproximaria da antropologia das emoções, tal como elaborada, por exemplo, por Lutz e White (1986) e por Rosaldo (1984). Similaridades mais diretas, que também pretendo explorar noutro espaço, poderiam ser traçadas com a ideia de ser afetado no trabalho de Jeanne Favret-Saada (1990; ver Goldman 2005). Acredito que, de uma forma geral, uma antropologia dos afetos está próxima daquilo que Viveiros de Castro $(2002,2009)$ vem propondo: a antropologia seria um experimento que envolve uma dimensão de ficção, e que assume para si a tarefa de tomar as ideias indígenas como conceitos (2002:123). Como já ressaltado, conceito comporta duas outras dimensões, as do afeto e do percepto, indispensáveis para o movimento, para o devir (Deleuze 2007). 


\section{Referências bibliográficas}

ALBERT, Bruce. 2002. "O ouro canibal e a queda do céu: uma crítica xamânica da economia política da natureza (yanomami)". In: B. Albert \& A. Ramos (orgs.), Pacificando o branco: cosmologias do contato norte-amazônico. São Paulo: Unesp. pp. 239-270.

ALBERT, Bruce \& KOPENAWA, Davi. 2010. La chute du ciel. Paroles d'un chaman yanomami. Paris: Plon.

ALMEIDA, Maria Inês. 2007. "Outro destino". Entrevista concedida por Eduardo Viveiros de Castro a Maria Inês de Almeida. Aletria, 16:20-36.

ASAD, Talal. 1986. "The concept of cultural translation in british social anthropology". In: J. Clifford \& G. Marcus (orgs.), Writing culture. The poetics and politics of ethnography. Berkeley: University of California Press. pp. 141-164.

BARCELOS NETO, Aristóteles. 2006. “'Doença de índio': o princípio patogênico da alteridade e os modos de transformação em uma cosmologia amazônica". Campos, 7(1):09-34.

BENJAMIN, Walter. 2001. "A tarefa-renúncia do tradutor": In: W. Heidermann (org.), Clássicos da teoria da tradução. vol. 1: Alemão-português. Florianópolis: Editora da Universidade Federal de Santa Catarina. pp. 189-215.

BERMAN, Antoine. 1995. Pour une critique des traductions: John Donne. Paris: Éditions Gallimard.

- 2002. A prova do estrangeiro: cultura e tradução na Alemanha Romântica. Bauru, SP: EDUSC. -2007. A tradução e a letra ou o albergue do longínquo. Rio de Janeiro: 7 Letras.

BUCHILlET, Dominique. 1991. "A antropologia da doença e os sistemas oficiais de saúde". In: D. Buchillet (org.), Medicinas tradicionais e medicina ocidental na Amazônia. Belém: MPEG/UEP/Edições Cejup. pp. 21-44.

BURCHILL, Louise. 2007. "Deleuze comme 'traductologue'? Ou le temps de traduire". Multitudes, 27(2):187-197.

CANGUILHEM, Georges. 1984. Le normal et le pathologique. $5^{\mathrm{a}}$ ed. Paris: Quadrige/PUF.

CARNEIRO DA CUNHA, Manuela. 1998. "Pontos de vista sobre a Floresta Amazônica: xamanismo e tradução". Mana. Estudos de Antropologia Social, 4(1):7-23.

DELEUZE, Gilles. 1968. Spinoza et le problème de l'expression. Paris: Les Éditions de Minuit. . 1978. Spinoza: Cours Vincennes. Paris. Ms. . 1986. "The intellectual and politics: Foucault and the prison" (interview by Paul Rabinow and Keith Gandal). History of the Present, 2:1-2, 20-21.

- 1987. Proust e os signos. Rio de Janeiro: Forense.

- 1997. Mil Platôs: capitalismo e esquizofrenia. vol. 4. São Paulo: Ed.34. - 1992. O que é a filosofia? Rio de Janeiro: Editora 34.

. 1995. "L'immanence: une vie...". Philosophie, 47:3-7.

_.1997. Crítica e clínica. Rio de Janeiro: Editora 34.

_ 2007. Conversações. São Paulo: Ed. 34.

DERRIDA, Jacques. 2003. Torres de Babel. Belo Horizonte: UFMG.

- 2005. Qu'est-ce qu'une traduction relevante? Paris: Ed. De l'Herne.

ESPINOSA, Bento de. 2007. Ética. Belo Horizonte: Autêntica.

FAVRET-SAADA, Jeanne. 1990. "Être affecté". Gradhiva. Revue d'Histoire et d'Archives de l'Anthropologie, 8:3-9. 
FOLLÉR, May-Lis. 2004. "Intermedicalidade: a zona de contato criada por povos indígenas e profissionais de saúde". In: E. Langdon \& L. Garnelo (orgs.), Saúde dos povos indígenas: reflexões sobre antropologia participativa. Rio de Janeiro: Contra Capa/ ABA. pp.129-147.

GALLOIS, Dominique. 1991. "A categoria 'doença de branco': ruptura ou adaptação de um modelo etiológico indígena?". In: D. Buchillet (org.), Medicinas tradicionais e medicina ocidental na Amazônia. Belém: Edições CEJUP. pp.175-206.

GARNELO, Luiza. 2003. Poder, hierarquia e reciprocidade: saúde e harmonia entre os Baniwa do Alto Rio Negro. Rio de Janeiro: Editora Fiocruz.

— \& WRIGHT, Robin. 2001. "Doença, cura e serviços de saúde. Representações, práticas e demandas baniwa". Cadernos de Saúde Pública, $17(2): 273-284$.

GOLDMAN, Marcio. 1999. "O que fazer com selvagens, bárbaros e civilizados?". In: Alguma antropologia. Rio de Janeiro: Relume-Dumará. pp.77-82. . 2005. "Jeanne Favret-Saada, os afetos, a etnografia". Cadernos de Campo, 13:149-153.

GOOD, Biron J. 1994. Medicine, rationality, and experience: an anthropological perspective. Cambridge, UK: Cambridge Univ. Press.

HARDT, Michael. 1996. Gilles Deleuze: um aprendizado em filosofia. São Paulo: Editora 34.

HOLBRAAD, Martin. 2003. "Estimando a necessidade: os Oráculos de Ifá e a verdade em Havana". Mana. Estudos de Antropologia Social, 9(2):39-77.

LANGDON, Esther J. 1991. "Percepção e utilização da medicina ocidental dos índios Sibundoy e Siona no sul da Colômbia". In: D. Buchillet (org.),
Medicina tradicional e medicina ocidental na Amazônia. Belém: Museu Goeldi. pp. 207-227.

. 2001. "A tolerância e a política de saúde do índio no Brasil: são compatíveis os saberes biomédicos e os saberes indígenas?". In: L. D. Grupioni; L. Vidal \& R. Fischmann (orgs.), Povos indígenas e tolerância: construindo práticas de respeito e solidariedade. São Paulo: Edusp. pp. 157-165. 2004. "Uma avaliação crítica da atenção diferenciada e a colaboração entre antropologia e profissionais de saúde". In: E. Langdon \& L. Garnelo (orgs.), Saúde dos povos indígenas: reflexões sobre antropologia participativa. Rio de Janeiro: Contra Capa/ ABA. pp. 33-51.

· 2005. "A construção sociocultural da doença e seu desafio para a prática médica". In: R. G. Baruzzi \& C. Junqueira (orgs.), Parque Indígena do Xingu. Saúde, cultura e história. São Paulo: Ed. Terra Virgem. pp. 115-133.

LATOUR, Bruno. 1989. "Traduire les intérêts des autres". In: La science en action. Paris: La Découverte. pp. 163-235. - 1997. Jamais fomos modernos: ensaio de antropologia simétrica. Rio de Janeiro: Editora 34.

LUKÁCS, Georg. 1974. História e consciência de classe. Estudos de dialética marxista. Lisboa: Escorpião.

LUTZ, Catherine. 1986. "Emotion, thought, and estrangement: emotion as a cultural category". Cultural Anthropology, 1:287-309.

LUTZ, Catherine \&WHITE, Geoffrey M. 1986. "The anthropology of emotions". Annual Review of Anthropology, 15: 405-436.

MORAES, Jacques Marcelo. 2008. "O tradutor e seus afetos". Remate de Males, 28(2): 227-239. 
PEREIRA, Pedro Paulo Gomes. 2012. "Variations around water: bodies, encounters and translation processes". Vibrant - Virtual Brazilian Anthropology, 9(1):156-180.

PEREZ GIL, Laura. 2007. "Políticas de saúde, pluralidade terapêutica e identidade na Amazônia". Saúde e Sociedade, 16(2):48-60.

RICOEUR, Paul. 2004. Sur la traduction. Paris: Bayard.

ROSALDO, Michelle Z. 1984. "Toward an anthropology of self and feeling". In: R. Seweder \& R. LeVine (orgs.), Culture theory. Essays on mind, self and emotion. Harvard: Cambridge University Press. pp. 137-157.

SÉVÉRAC, Pascal. 2005. Le devenir actif chez Spinoza. Paris: Honoré Champion Éditeur.

TAMBIAH, Stanley J. 1995. "Rationality, relativism the translation and commensurability of cultures". In: Magic, science and the scope of rationality. Harvard: Cambridge University Press. pp. 111-140.

TAUSSIG, Michael. 1992. "Reification and the consciousness of the patient". In: The nervous system. New York/London: Routledge. pp. 83-106. - 1993. Xamanismo, colonialismo e o homem selvagem. Um estudo sobre o terror e a cura. São Paulo: Paz e Terra. VIVEIROS DE CASTRO, Eduardo. 2000. "Os pronomes cosmológicos e o perspectivismo ameríndio". In: É. Alliez (org.), Gilles Deleuze: uma vida filosófica. São Paulo: Ed. 34. pp. 421-450. . 2002. "O nativo relativo". Mana. Estudos de Antropologia Social, 8(1):113148.

. 2004. "Perspectival anthropology and the method of controlled equivocation". Tipití (Journal of the Society for the Anthropology of Lowland South America), 2(1):3-22.
2009. Metaphysiques cannibales. Paris: Presses Universitaires de France.

ZOURABICHVILI, François. 2004. O vocabulário de Deleuze. Rio de Janeiro: Relume-Dumará. 


\section{Resumo}

Este artigo volta-se simetricamente para profissionais de saúde que atuam em contextos indígenas, elaborando as seguintes perguntas: O que acontece com profissionais de saúde que se veem diretamente relacionados a concepções diferenciadas de corpo, saúde e doença? O que sucede quando as práticas de saúde se dão num processo de tradução da própria conceituação do que seja saúde? De que forma esses profissionais são afetados por essa experiência com a alteridade radical? $\mathrm{Na}$ busca de refletir sobre essas indagações, o texto se detém nas histórias de uma médica e de uma enfermeira, destacando motivos constantes em suas narrativas, que nos contam algo sobre limitações, limites e processos de tradução. O cenário descrito talvez possa matizar a percepção de uma biomedicina homogênea e de profissionais de saúde exclusivamente vinculados ao poder - sempre envoltos em relações reificadas e reificadoras.

Palavras-chave Saúde indígena, Intermedicalidade, Tradução, Antropologia dos afetos.

\section{Abstract}

The present article symmetrically deals with health professionals who work in indigenous contexts, developing the following questions: what happens to health professionals who find themselves directly relating to different conceptions of body, health and disease? What happens when health practices take place in the context of the process of translating the very concept of health itself? How are these professionals affected by the experience of contact with radical otherness? In seeking to reflect upon these questions, we focus upon the stories of a doctor and a nurse, highlighting points contained in their narratives which tell us something about constraints, limits and translation processes. The scenario described here might temper belief in a homogeneous biomedicine and healthcare professionalism that is exclusively rooted in power: always wrapped in reified and reifying relations.

Key words Indigenous health, Intermedicality, Translation, Anthropology of affect. 